METAL FORMING 


\title{
METAL FORMING
}

\section{Tool Profiles and Flow}

\author{
T. Z. BLAZYNSKI
}

Dept. of Mechanical Engineering, University of Leeds

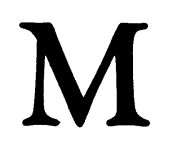


(C) T. Z. Blazynski 1976

Softcover reprint of the hardcover 1st edition 1976

All rights reserved. No part of this publication may

be reproduced or transmitted, in any form or by any means, without permission

This book is sold subject to the standard conditions of the Net Book Agreement

First published 1976 by

THE MACMILLAN PRESS LTD

London and Basingstoke

Associated companies in New York Dublin

Melbourne Johannesburg and Madras

ISBN 978-1-349-02863-4 ISBN 978-1-349-02861-0 (eBook)

DOI 10.1007/978-1-349-02861-0

Filmset by Thomson Press (India) Ltd, New Delhi 
To Pauline 


\section{Preface}

As the industrial importance of metal-forming processes has grown constantly during the last three decades, so have intensive experimental and theoretical investigations of the basic nature, properties and mechanical parameters of these various manufacturing operations. Although a substantial volume of literature exists in the form of both books and papers, the emphasis in presenting the available information is usually on the overall mechanics of the processes. The study of the patterns of metal flow, their relation to the geometry of the pass and their link with the incidence of faults in the product, appears less prominent.

The present book is designed to redress the balance and, by doing so, to stress the practical importance of a well-informed, rational approach to the problem of assessing the optimum conditions of metal flow. In particular, the book aims to draw attention to the general problem of the effects of the inhomogeneous or redundant deformation, to illustrate its physical and practical significance in a number of basic metal-forming processes, and to show how the choice of the geometry of the pass can alleviate severe working conditions.

The book is intended primarily for engineers and industrial metallurgists concerned with metal forming, and for postgraduate students of engineering and metallurgy. It can also, however, be used profitably for teaching specialised, usually final-year, optional undergraduate courses. To satisfy these requirements, the complex theory of plasticity has been avoided. In fact the mathematical content has been minimised as far as is compatible with clarity, and its standard has generally been maintained at undergraduate level. To cater for the slightly diverse interests of the two main groups of potential readers, the contents are divided into three parts. Part I provides analytical and experimental tools for the study of metal flow, with chapter 2 briefly reviewing the existing range of analytical approaches, and chapter 3 giving the necessary physical means of redundant strain measurements. Part II is concerned in detail with the incidence, pattern and magnitude of redundant effects in the 
rotary tube-making, wire, rod and tube-drawing operations, in deep drawing and stretch forming of axisymmetric components, and in the conventional impact and hydrostatic extrusion processes. Part III, comprising chapters 9 and 10, reviews the established rational design concepts for the geometry of metal-working passes, and proposes two new concepts of tool design. The relative advantages of the various design techniques are illustrated in a selection of forming processes.

Many of the graphs, sketches and numerical data tables that illustrate the text have been previously published. The sources of illustrative items are acknowledged in the appropriate figure legends.

My sincere thanks are due to those of my former and present colleagues who, over a period of some twenty years, have contributed in many ways to the gathering of a substantial proportion of the data used in this book. Finally, I gratefully acknowledge my wife's help with the preparation of the manuscript, and her patience during the period of writing. 


\section{Contents}

Preface

vii

\section{PART I GENERAL ANALYSIS}

Chapter 1 Introduction

1.1 Metal-forming processes

1.2 Types and nature of deformations 4

1.3 Friction and inhomogeneity 6

1.4 Effects of redundant shears 7

Chapter 2 Techniques of Analysis

2.1 Stress and strain redundancy factors 10

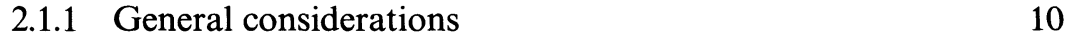

2.1.2 Yield stress, strain hardening and generalised strain 11

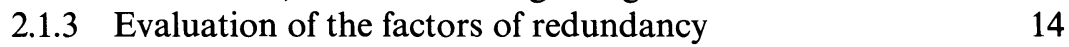

$\begin{array}{ll}2.2 \text { Analytical stress determination } & 18\end{array}$

2.2.1 Introduction 18

$\begin{array}{ll}\text { 2.2.2 The equilibrium method } & 19\end{array}$

2.2.3 The slip-line analysis $\quad 20$

2.2.4 Upper-bound technique 24

$\begin{array}{ll}2.2 .5 & \text { Visioplasticity } \\ & 26\end{array}$

Chapter 3 Experimental Determination of Redundant Deformation

3.1 Introduction 30

3.1.1 Incrementality 30

3.1.2 Grids, inserts and laminates 32

3.1.3 Model materials and prototypes 33

3.2 The use of model materials 33

3.2.1 Model and prototype similitude 33 
3.2.2 Materials and their properties 38

3.2.3 Assessment of mean strain rate 46

3.3 The insert and laminate techniques 56

3.3.1 Preparation of specimens 56

3.3.2 Measurement of redundant shears 57

3.3.3 The effect of homogeneous strain $\quad 60$

3.3.4 Incremental summation of strain 62

3.4 The grid technique 63

3.4.1 Square and circular grids 63

$\begin{array}{ll}3.4 .2 & \text { Applicability to visioplasticity }\end{array}$

3.4.3 Summation of effects 65

\section{PART II INCIDENCE, PATTERN AND MAGNITUDE OF REDUNDANT DEFORMATION}

\section{Chapter 4 Classification of Processes}

4.1 Introduction 69

4.2 Stress system classification $\quad 69$

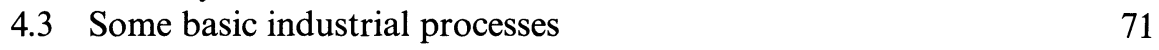

$\begin{array}{lll}\text { 4.3.1 Rotary operations } & 71\end{array}$

4.3.2 Drawing operations $\quad 80$

4.3.3 Extrusion 83

Chapter 5 Redundancy in Rotary Operations

$\begin{array}{lll}5.1 & \text { Tube-making processes } & 88\end{array}$

5.1.1 Introduction 88

5.1.2 Incidence and type of redundant shears $\quad 89$

5.1.3 Redundancy factors 90

5.1.4 Geometry of the processes 93.

5.1.5 Mechanics of the processes 101

5.2 Piercing 115

5.2.1 2 and 3-roll systems 115

$\begin{array}{ll}\text { 5.2.2 Influence of process parameters } & 123\end{array}$

$\begin{array}{ll}\text { 5.2.3 Cavitation } & 128\end{array}$

5.3 High-ratio tube-elongating processes 133

$\begin{array}{lll}\text { 5.3.1 Assel elongating } & 133\end{array}$

5.3.2 Secondary piercing 137

5.3.3 Combined piercing-elongating 143

$\begin{array}{ll}5.4 & \text { Triangulation in tube making } \\ & 149\end{array}$

5.4.1 The origin, effect and measurement of triangulation $\quad 149$

5.4.2 Incidence of triangulation in individual processes $\quad 152$

Chapter 6 Wire, Rod and Tube Drawing 
6.2 Rod and wire drawing

6.2.1 Flow through conical dies 158

$\begin{array}{ll}\text { 6.2.2 Methods of analysis } & 162\end{array}$

6.2.3 Pass geometry, material properties and redundancy $\quad 170$

6.2.4 Redundancy and mode of flow 180

$\begin{array}{lll}6.3 & \text { Tube drawing } & 184\end{array}$

$\begin{array}{ll}\text { 6.3.1 Introduction } & 184\end{array}$

6.3.2 Analytical treatment 185

6.3.3 Drawing systems and redundancy 200

Chapter 7 Deep Drawing and Stretch Forming

7.1 Characteristic features 222

7.1.1 Introduction 222

7.1.2 Drawing of cylindrical cups 223

7.1.3 Stretch forming 225

$\begin{array}{lll}7.2 & \text { Redundant deformation } & 227\end{array}$

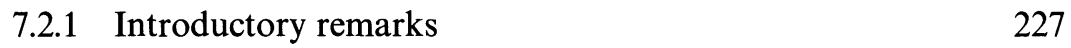

7.2.2 Flange wrinkling 228

$\begin{array}{ll}7.2 .3 & \text { Bending and unbending } 228\end{array}$

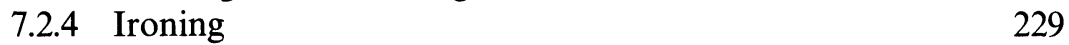

$\begin{array}{ll}7.3 \text { Analytical considerations } & 230\end{array}$

$\begin{array}{ll}\text { 7.3.1 Introduction } & 230\end{array}$

7.3.2 Deep drawing of cylindrical cups 231

7.3.3 Conventional stretch forming 239

7.3.4 Dynamic stretch forming 241

7.4 Process parameters and metal flow 246

7.4.1 Deep drawing of cups 246

7.4.2 Conventional stretch forming 252

7.4.3 Dynamic stretch forming 254

Chapter 8 Extrusion

8.1 Introduction 262

8.2 Analytical considerations 264

8.2.1 Homogeneous and redundant strains 264

8.2.2 Conventional extrusion 265

8.2.3 Impact extrusion 270

8.2.4 Hydrostatic extrusion 276

8.3 Flow and redundancy 280

8.3.1 General comments 280

8.3.2 Conventional extrusion of rod 280

8.3.3 Characteristic features of impact extrusion 287

8.3.4 Hydrostatic extrusion 294

8.3.5 Drawing-augmented hydrostatic extrusion of bar 297

8.3.6 Conventional and hydrostatic extrusion of bimetallic rod 299 
xii

PART III TOOL DESIGN

Chapter 9 Concepts of Tool Design

$\begin{array}{lll}9.1 & \text { Introduction } & 309\end{array}$

9.2 Some specific design solutions 313

9.2.1 Rotary operations 313

9.2.2 Extrusion and drawing 321

$\begin{array}{lll}9.3 & \text { Theoretical design concepts } & 328\end{array}$

9.3.1 Deformation and strain-rate concepts 328

9.3.2 Application to rotary processes 329

9.3.3 Application to drawing and extrusion 334

9.3.4 Computer-aided design 339

Chapter 10 Tools and Redundancy

10.1 Introduction 342

10.2 Rotary processes 342

10.2.1 Primary tube-piercing 342

10.2.2 Assel elongating 347

10.2.3 Secondary tube-piercing 349

10.2.4 Combined piercing-elongating $\quad 356$

$\begin{array}{lll}10.3 \text { Extrusion } & 361\end{array}$

10.3.1 Extrusion of rod 361

10.3.2 Tube extrusion 362

10.3.3 Drawing-augmented hydrostatic extrusion of bar 366

10.4 Concluding remarks 368

Author Index 371

Subject Index $\quad 374$ 